\title{
Potentiodynamic Corrosion Characterization of Hybrid Aluminium Composites for Advanced Engineering Applications
}

\author{
Santhosh N, Manjunath N, Mahesh H R
}

\begin{abstract}
Corrosion characterization of Aluminium composites is a significant study planned for assessing the capability of utilizing the materials for aviation and automobile parts. Aluminium 5083 is a particular class of alloys which is known for its corrosion resistance in extraordinary conditions and is utilized in aerospace components. However, the experimentations on impact of reinforcements, for example, the effect of Silicon carbide and Flyash on corrosion properties of Aluminium 5083 alloys is still in its incipient stage and not much literature is available outlining the corrosion attributes. The present work includes the fabrication of Aluminium 5083 - Silicon carbide Flyash composites and investigation of the corrosion conduct of these composites. The composites are fabricated by stir casting procedure, considering silicon carbide particulates varied in the scope of $3 \mathrm{wt. \%}$ to $9 \mathrm{wt} . \%$ at an intermittent intervals of $2 \mathrm{wt} . \%$. The composition of fly ash in the present work is limited to $5 \mathrm{wt} . \%$ for restricting the porosity after conducting preliminary trials. The composite materials considered in this research are assessed for corrosion by Potentio-dynamic test, which is accomplished utilizing a test arrangement comprising of five mouth jar with calomel electrode and a working cathode (comprising of the specimen held rigidly with a copper wire and secured with Teflon tape notwithstanding a region of one square centimeter exposed to the electrolyte). The anodic and cathodic potentio-dynamic polarization estimations are acquired as tafel plots in the PC that is interfaced with the test arrangement. The outcomes reveal that the corrosion current (Icorr) increases with the increase in the weight percentage of Silicon carbide in the metal matrix. The electrolyte considered for the potentio-dynamic test is and $1 \mathrm{M}$ $\mathrm{HCl}$ (acidic) medium.
\end{abstract}

Keywords: Aluminium, Metal, Matrix, Composite, Potentiodynamic, Corrosion.

\section{INTRODUCTION}

Aluminium Composites are a unique class of composite materials with greater strength characteristics that can yield MMCs with altogether improved properties (for example lesser density, greater young's modulus and higher yield

Revised Manuscript Received on February 05, 2020.

* Correspondence Author

Santhosh N*, Department of Mechanical and Automobile Engineering, CHRIST (Deemed to be University, Bangalore, India. Email: santhosh.n@christuniversity.in

Manjunath N, Department of Sciences and Humanities, CHRIST (Deemed to be University), Bangalore, India. Email: manjunath.nanjappa@christuniversity.in

Mahesh H R, Department of Mechanical Engineering, Vivekananda Institute of Technology, Bangalore, India. Email: maheshhr009@gmail.com

(C) The Authors. Published by Blue Eyes Intelligence Engineering and Sciences Publication (BEIESP). This is an open access article under the CC BY-NC-ND license (http://creativecommons.org/licenses/by-nc-nd/4.0/)

strength) perfect for some potential automobile and aerospace applications. For instance, hybrid aluminium composites are particularly favorable for engineering applications with greater thermal conductivity and wear resistance [1 - 3]. A few SiCp/Al and Grp/Al composites have been space-qualified and are presently used in correspondence satellites [4]. Metal framework composites are the financially accessible composites that can be fabricated utilizing new methods and can yield better shaped items with good properties [5]. The greater part of the work in this developing front has utilized Al composites as the base material, most generally the hypereutectic, hypoeutectic, and A356 alloys [6].

MMCs have likewise started to replace traditional materials in Aerospace parts, automotive components, Computers, Audio and Video hardware, and Sporting applications. Compressive strength and rigidity, just as the hardness at room and elevated temperatures, are likewise considered essentially, bringing about an improvement in the wear resistance of the composite material. Further, the increase in the weight percentage of reinforcements could fundamentally change the corrosion conduct of these materials [7]. While physical-mechanical properties of MMCs have been broadly considered, generally little data is available related to the corrosion conduct of these MMCs. Thus, corrosion has ended up being a significant issue in all the designing spaces. It is a genuine impediment for basic trustworthiness of numerous aerospace and automotive parts especially in case of engine components [8].

Aluminum and its alloys have been utilized as a matrix for an assortment of applications: However reinforcements are a key consideration for fabrication of the composites. Likewise, the fabrication of these composites is significantly important to fulfill numerous application prerequisites [9$10]$.

The effect of reinforcements are important to understand the significance of the composites fabricated. This is especially obvious when the matrix is a functional metal or alloy, for example, aluminum and its alloys, which are used to enhance the conductivity or semi conductivity, by reinforcing it alongside graphite or silicon carbide. Further, the corrosion rate for an Al-alloy reinforced with graphite is multiple times higher than for base aluminium alloy, because of galvanic corrosion and the higher rate of oxidation at the cathodic locales [11 - 13]. Corrosion is also a key factor in which suitable reinforcements, have to be selected to reinforce aluminum alloys without actuating galvanic corrosion [14 - 15]. 
Corrosion has likewise significant effect because of the material loss that it results in [16]. Corrosion investigations of aluminum and aluminum composites have derived significant consideration by researchers in view of their wide modern applications and monetary contemplations [17 - 21]. Aluminum and aluminum composites have evolved as a suitable matrix material in aircraft and in some material handling applications [22].

Because of their wide applications, aluminium and their alloys often interact with acids or bases during electrochemical processes and are broadly considered for a variety of components [23]. The corrosion of different metals and alloys in acidic and basic media are of major concern in aerospace and automobile applications and needs to be understood keenly for expanding the horizon of corrosion studies of composite materials [24].

\section{MATERIALS AND METHODS}

\section{A. Materials}

Aluminium AA 5083 alloy is selected as matrix phase in the present work, while Silicon carbide particles having particle size in the range of 40 to $50 \mu \mathrm{m}$ and Fly ash flakes are chosen as reinforcements. The composition of the Aluminium 5083 alloy considered in the present work is given in Table I.

Table - I Composition of Aluminium AA 5083 Alloy

\begin{tabular}{|c|c|}
\hline Element & \% Present \\
\hline $\mathbf{S i}$ & 0.4 \\
\hline $\mathbf{F e}$ & 0.4 \\
\hline $\mathbf{C u}$ & 0.1 \\
\hline $\mathbf{M n}$ & $0.4-1.0$ \\
\hline $\mathbf{M g}$ & $4.0-4.9$ \\
\hline $\mathbf{Z n}$ & 0.25 \\
\hline $\mathbf{T i}$ & 0.15 \\
\hline $\mathbf{C r}$ & $0.05-0.25$ \\
\hline $\mathbf{A l}$ & Balance \\
\hline
\end{tabular}

Aluminium AA 5083 is a specific class of non-heat treatable aluminium alloys which is having the following characteristic as mentioned below in the Table II. It is an alloy which resists corrosion in extreme environments and has exceptional strength characteristics among all the other grades of aluminium alloys.

Table - II Property Table of Aluminium AA 5083 Alloy

\begin{tabular}{ll}
\hline Property & Value \\
\hline Density & $2650 \mathrm{~kg} / \mathrm{m}^{3}$ \\
Melting Point & $570^{\circ} \mathrm{C}$ \\
Modulus of Elasticity & $72 \mathrm{GPa}$ \\
Electrical Resistivity & $0.058 \times 10^{-6} \Omega . \mathrm{m}$ \\
Thermal Conductivity & $121 \mathrm{~W} / \mathrm{m} . \mathrm{K}$ \\
Thermal Expansion & $25 \times 10^{-6} / \mathrm{K}$ \\
\hline
\end{tabular}

\section{B. Methods}

Aluminium (5083) alloy, Silicon carbide particles, Flyash are weighed for different weight fractions. The silicon carbide particles and flyash are initially preheated at a temperature of $250{ }^{\circ} \mathrm{C}$ for 10 minutes to help improve wettability with the Al (5083) alloy. The Al (5083) alloy ingots are charged into a gas-fired crucible furnace and heated to a temperature of $750{ }^{\circ} \mathrm{C}$ (above the liquidus temperature of the alloy) and the liquid alloy is then allowed to cool in the furnace to a semi solid state at a temperature of about $630{ }^{\circ} \mathrm{C}$, which is followed by degasification with the help of degassing fluxes composed of chlorine and fluorine containing salts. The preheated silicon carbide and fly ash flakes are wrapped along with $1 \mathrm{~g}$ of $\mathrm{Mg}$ in an aluminium foil and is added at this temperature and stirring of the slurry is performed manually for 5 minutes. The composite slurry is once again superheated to $750{ }^{\circ} \mathrm{C}$ and a second stirring is performed using a mechanical stirrer at a speed of $300 \mathrm{rpm}$ to help improve the dispersion of the reinforcements in the molten $\mathrm{Al}$ (5083) alloy. The molten aluminium alloy is then poured to preheated die and allowed to solidify, the solidified casting is then removed from the die and machined to required specimen size. The different composition of the specimens fabricated for present work is as given in the table -3 and the schematic flow chart of the methodology carried out in the present work is illustrated in the figure 1.

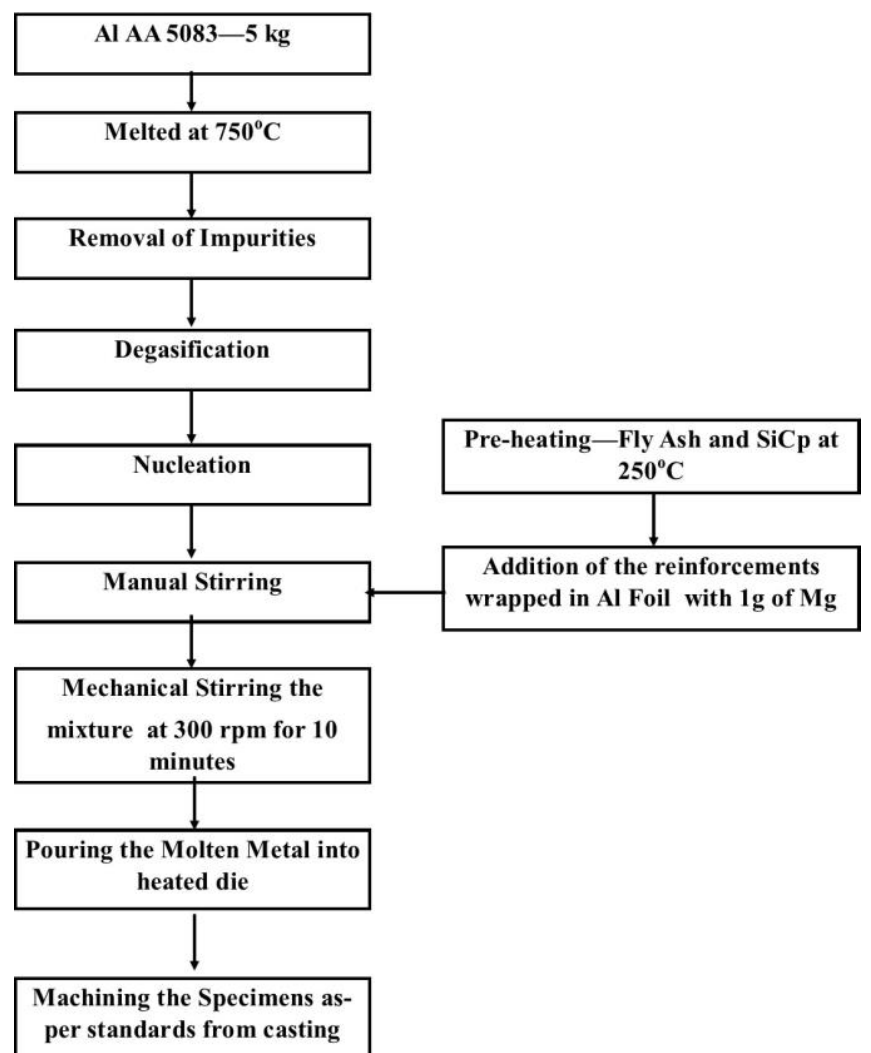

Fig - 1. Flow Chart of the Methodology

The potentio-dynamic experiments are carried out on duly prepared specimens such that the area exposed to electrolytic medium is $1.0 \mathrm{~cm}^{2}$, for this purpose, a Teflon tape is used. Before experimentations, the specimens are effectively polished with different grades of emery papers right from 180 grade emery to 2000 grade emery, followed by very fine polishing with disc polisher using alumina paste to get mirror surface. The specimens are then dried and stored in desiccators to avoid moisture before carrying out the corrosion characterization. 
The initial weights of the specimens after thorough cleaning is noted using a high precision digital balance.

Further, a typical stock solution of hydrochloric acid is prepared using laboratory grade Concentrated $\mathrm{HCl}$ solution and double distilled water and standardized by potentiometric methods and volumetric techniques.

Hydrochloric acid medium of $1.0 \mathrm{M}$ is prepared by taking $88 \mathrm{ml}$ of concentrated $\mathrm{HCl}$ in a 1 litre beaker and adding double distilled water to make up the solution to 1 litre and standardized by volumetric methods using Phenolphthalein indicators.

\section{Potentiodynamic Corrosion}

Potentiodynamic Corrosion tests are carried out on specimens prepared for experimentation in such a way that approximately one square $\mathrm{cm}$. of surface area is exposed to the corrosion medium of $1 \mathrm{M}$ hydrochloric acid. The potentiodynamic current and potential curves are recorded by polarizing the specimen in a $\mathrm{CH}$ make potentiometer setup interfaced with the Computer through data logger and LabVIEW software at a scan rate of 0.01 Volts per second.

\section{RESULTS AND DISCUSSIONS}

The potentio-dynamic tests carried out has yielded tafel plots. It is clear from the tafel plots that the corrosion current as well as the corrosion rate decreases with the increase in the weight percentage of silicon carbide in the aluminium 5083 fly ash composite subsystem. The table - III gives the variation of corrosion rate and corrosion rate with the percentage of silicon carbide.

Table - III Potentiodynamic Corrosion in $1 \mathrm{M} \mathrm{HCl}$

\begin{tabular}{|c|c|c|c|}
\hline Sl. No. & $\begin{array}{c}\text { Specimen } \\
\text { Designation }\end{array}$ & $\begin{array}{c}\text { Icorr } \\
(\mathbf{E}-4) \mathbf{A}\end{array}$ & $\begin{array}{c}\text { Corrosion rate } \\
(\mathbf{E}-\mathbf{2}) \mathbf{g} / \mathbf{m V}\end{array}$ \\
\hline $\mathbf{1 .}$ & A3S5F & 4.624 & 4.2541 \\
\hline $\mathbf{2 .}$ & A5S5F & 4.432 & 4.1664 \\
\hline $\mathbf{3 .}$ & A7S5F & 2.921 & 2.5743 \\
\hline $\mathbf{4 .}$ & A9S5F & 2.711 & 2.3741 \\
\hline
\end{tabular}

The potentio-dynamic corrosion studies have given an overview of variation in potential with respect to the variation in corrosion current. The tafel plots demonstrate that the corrosion current decreases with the increase in percentage of silicon carbide content. Figures 2, 3, 4 and 5 represent the tafel plots for different specimens as designated in the table III.

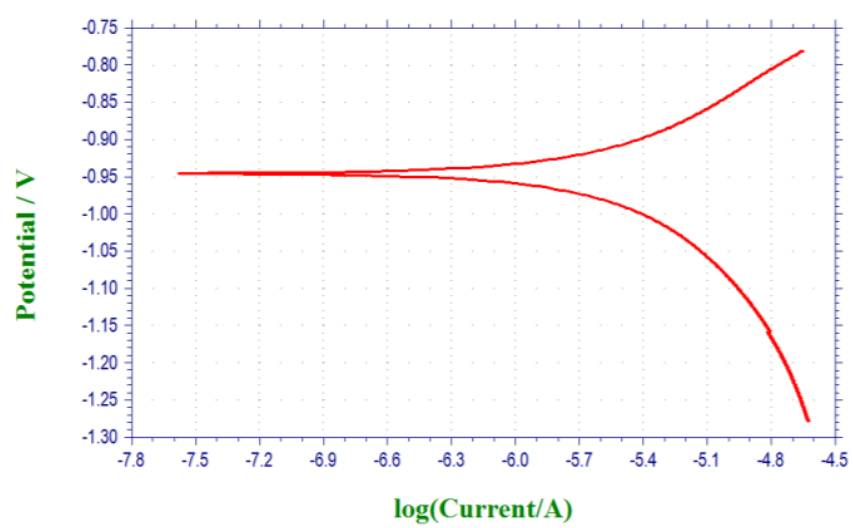

Fig - 2. Tafel Plot for A3S5F Specimen

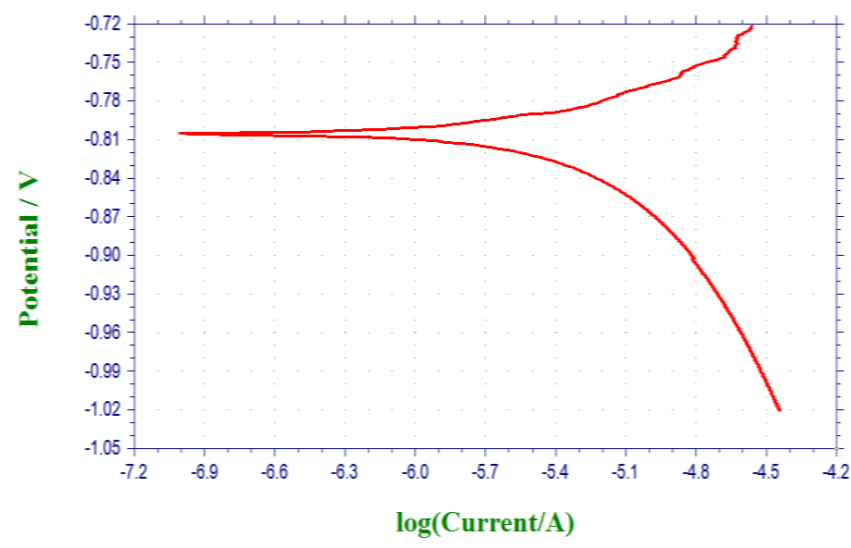

Fig - 3. Tafel Plot for A5S5F Specimen

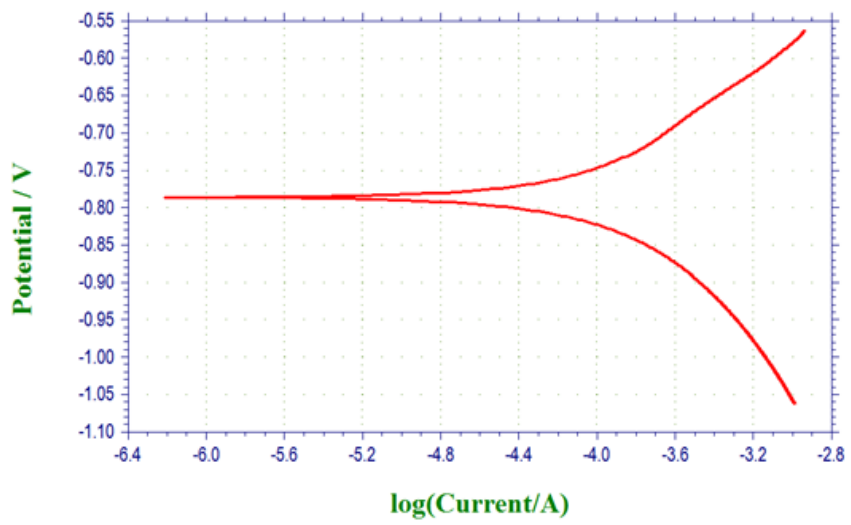

Fig - 4. Tafel Plot for A5S7F Specimen

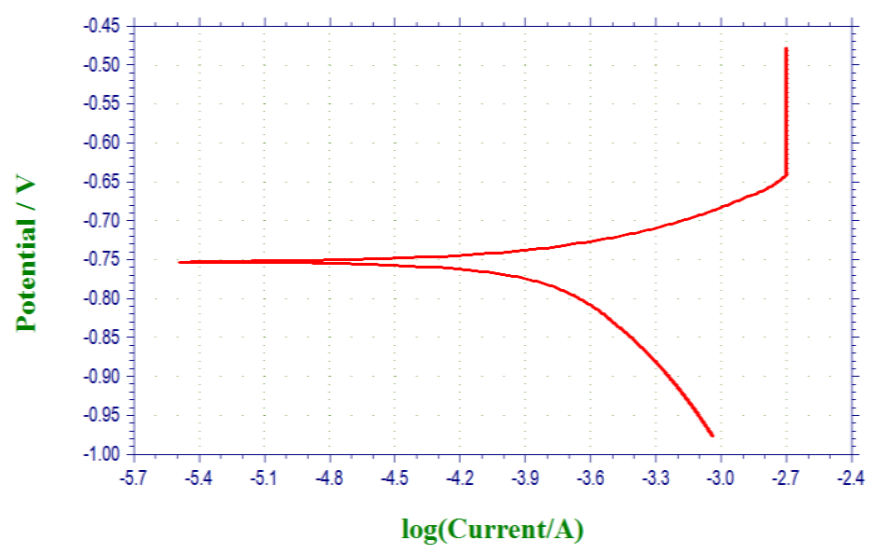

Fig - 5. Tafel Plot for A5S9F Specimen

The corrosion rate thus decreases with the addition of silicon carbide due to the formation of passive oxide layer with time that acts as a barrier and further inhibits the corrosion process.

\section{CONCLUSIONS}

$>$ The potentio-dynamic test carried out has provided tafel plots, whose interpretations have concluded that the addition of silicon carbide reduces the corrosion rate.

$>$ The addition of silicon carbide to the Aluminium 5083 Fly ash composite sub system decreases the corrosion rates due to passivation of electrolytic reactions. 
> The silicon carbide particles act as obstacles for pitting corrosion by occupying the dendrite arm spacing in the composite and avoid galvanic reactions.

> The Aluminium 5083/Silicon carbide/Fly ash hybrid metal matrix composite thus developed has shown enormous improvement in corrosion characteristics and is a potential material for use in aerospace components, since the parts of aircrafts demand better potentiodynamic corrosion resistance to maintain the structural integrity.

\section{ACKNOWLEDGMENT}

The authors wish to wholeheartedly acknowledge the management, faculty members and Heads of the departments of CHRIST (Deemed to be University) and Vivekananda Institute of Technology for their constant support guidance, encouragement and support towards accomplishing this research work and subsequent publication.

\section{REFERENCES}

1. Rawal S 2001 Metal-Matrix Composites for Space Applications Journal of Minerals, Metals \&Materials 14-17

2. A.P.Divecha, S.G.Fishman and S.D.Karmarkar, (1981) 'Silicon Carbide reinforced aluminium-a formable composite' Journal of Metals, Vol.22 No.4 pp.211-214.

3. David McDanels (1985) Analysis of stress-strain, fracture and ductility behaviour of aluminium matrix composites containing discontinous silicon carbide reinforcements, Metallugical Transactions, Vol11, No12 pp.311-315

4. N. Wang, Z. Wang and G.C. Weatherly, "Formation of Magnesium Aluminate (spinel) in Cast SiC Particulate Reinforced Al (a356) Metal Matrix Composites", Metall. Mater. Trans., 23 (1992) 1423-1431.

5. D.J.Lloyd, H.Lagace, A.Mcleod and P.L.Morris, (1989) 'Microstructural aspects of aluminium silicon carbide particulate composites produced by a casting method, Journal of Materials Science and Engineering' Vol.11, No.19 pp 73-80.

6. F.A.Badia and K.P.Rohatgi,(1969) 'Microstructural aspects of aluminium silicon carbide particulate composites produced by a casting method', Trans.American Foundryman's Society, Vol 79 No 11,pp402.

7. F.A.Badia, D.F.McDonald and J.R.Pearson, (1971) 'Microstructural aspects of aluminium silicon carbide particulate composites produced by a casting method', Trans.American Foundryman's Society, Vol 79 No 11, pp 265

8. F.A.Badia, (1971) 'Microstructural aspects of $\mathrm{zn}$ silicon carbide particulate composites produced by a casting method,' Trans.American Foundryman's Society, Vol 79 No 23, pp347.

9. S.V.Nair, J.K.Tien and R.C.Bates, (1984) 'SiC reinforced aluminium metal matrix composites' International Metal Reviews, Vol. 30 No.6 pp. 275.

10. R.D.French, A.Levitt and M.H.Richman, (1970) 'Microstructural aspects of Al-6061 silicon carbide particulate composites produced by a casting method', American Ceramic Society Bulletin, Vol 49 No16, pp 580.

11. Abdel-Gaber, A.M., Khamis, E., Abo-EI Dahab, Sh., Adeel, H., 2008. Inhibition of aluminum corrosion in alkaline solutions using natural compound. Mater. Chem. Phys. 109, 297-305.

12. Ating, E.I., Umoren, S.A., Udousoro, I.I., Ebenso, E.E., Udoh, A.P., 2010. Leaves extract of Ananas sativum as green corrosion inhibitor for aluminium in hydrochloric acid solutions. Green Chem. Lett. Rev. 3, 61-68.

13. Badaway, W.A., AlKharafi, F.M., El-Azab, A.S., 1999. Electrochemical behavior and corrosion inhibition of Al, Al-6061 and $\mathrm{Al}-\mathrm{Cu}$ in neutral aqueous solutions. Corros. Sci. 41, 709-727.

14. Brett, C.M.A., 1990. The application of electrochemical impedance techniques to aluminium corrosion in acidic chloride solution. J. Appl. Electrochem. 20, 1000-1003.

15. Brett, C.M.A., 1992. On the electrochemical behaviour of aluminium in acidic chloride solution. Corros. Sci. 33, 203-210.

16. Brock, A.J., Wood, G.C., 1967. Hydroxyl ion and proton mobility during anodic oxidation of aluminium. Electrochem. Acta 12, 395-412.

17. Christian Vargel, 2004. Corrosion of Aluminium. Elsevier Ltd., NewYork.
18. El-Neami, K.K.H., Mohamed, A.K., Kenawy, A.S., Fouda, I.N., 1995. Inhibition of the corrosion of iron by oxygen and nitrogen containing compounds. Monatsh. Chem. J. 126, 369-376.

19. El-Sayed, A., 1997. Phenothiazine as inhibitor of the corrosion of cadmium in acidic solutions. J. Appl. Electrochem. 27, 193-200.

20. Foley, R.T., Nguyen, T.H., 1982. The chemical nature of aluminium corrosion. J. Electrochem. Soc. 129, 464-467.

21. Fontana, M.G., 1987. Corrosion Engineering, third ed. McGraw-Hill, Singapore.

22. Hart, R.K., 1957. The formation of films on aluminium immersed in water. Trans. Faraday Soc. 53, 1020-1027.

23. Kosting, P.R., Heins, C., 1931. Corrosion of metals by phosphoric acid. Ind. Eng. Chem. 23, 140-150.

24. Lenderink, H.J.W., Linden, M.V.D., De Wit, J.H.W., 1993. Corrosion of aluminium in acidic and neutral solutions. Electrochim. Acta 38, 1989-1992.

25. Santhosh N, U N Kempaiah, Ashwin C Gowda, Corrosion Characterization of Silicon Carbide and Fly Ash Particulates Dispersion Strengthened Aluminium 5083 Composites. Journal of Catalyst \& Catalysis. 2017; 4(2): 9-21p.

\section{AUTHORS PROFILE}

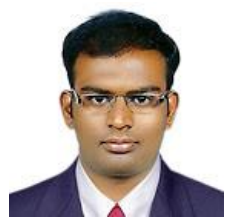

Dr. Santhosh N, currently working as an Assistan Professor in the department of Mechanical and Automobile Engineering, School of Engineering and Technology, CHRIST (Deemed to be University) has obtained his B.E., degree in Mechanical Engineering from Visvesvaraya Technological University, M.E., in Manufacturing Science and Engineering, and Ph.D., in Composite Materials from Bangalore University, He has to his credit more than 50 research articles published in Scopus indexed journals of very high impact factor and most of them belonging to Elsevier and Springer Publications. He has authored several books and chapters and is a recipient of several awards and accolades for his outstanding work in the domain of materials research. He is also regarded as a good teacher and has developed teaching pedagogy and methodologies for content delivery in subjects of Materials Science, Machine Design, Kinematics of Machines and Dynamics. $\mathrm{He}$ is a member of several technical societies and is actively involved in disseminating scientific principles and knowledge.

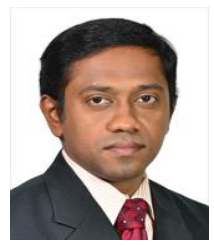

Dr. Manjunath N, currently working as an Assistant Professor in the department of Sciences and Humanities, School of Engineering and Technology, CHRIST (Deemed to be University), has obtained his Bachelor of Science degree from the prestigious Government Science College, Bangalore, M.Sc., and Ph.D., from Bangalore University, His areas of research include Graph theory, Mathematic Modelling for Materials research and fundamental design and development, He has published several research papers and has attended Several Conferences and Symposiums as keynote speaker. He is a member of several societies and organizations working for dissemination of mathematical knowledge for scientific progress.

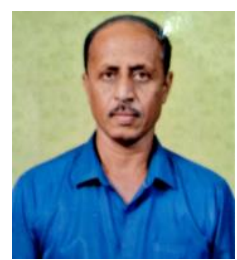

Prof. Mahesh H R, currently working as an Assistant Professor, Vivekananda Institute of Technology, has obtained his B.E., degree in Automobile Engineering, from PES College of Engineering, Mandya and M.Tech degree in Manufacturing Science and Engineering, He has vast industrial experience was involved in Heat Treatment and Automotive Industries for nearly two decades, He has to his credit several research papers and has attended several conferences. He is a good teacher known for his innovative teaching pedagogy in helping students understand the basics of engineering techniques through models and practical exposure, He has also worked in the domain of composites for advanced engineering applications and allied products.

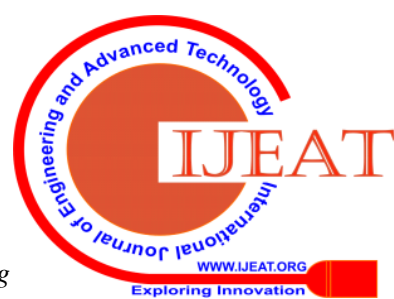

